\title{
Parapharyngeal Space Venous Malformation: An Imaging Mimic of Pleomorphic Adenoma
}

\author{
(D) C.M. Tomblinson, (D) G.P. Fletcher, DT.K. Lidner, (D) C.P. Wood, (D) S.M. Weindling, and (D).M. Hoxworth
}

\begin{abstract}
SUMMARY: Venous malformations in the parapharyngeal space are rare and may be challenging to diagnose with imaging secondary to multiple overlapping features with pleomorphic adenoma, which is much more commonly found in this region. While both lesions are $\mathrm{T1}$ isointense and $\mathrm{T} 2$ hyperintense relative to skeletal muscle and demonstrate contrast enhancement, more uniform T2 hyperintensity and progressive contrast pooling on delayed postcontrast TIWI may allow the radiologist to include venous malformation in the differential diagnosis. This is important because it has the potential to alter management from surgical resection to observation. The primary aim of this study was to review the imaging appearance of parapharyngeal venous malformations through a retrospective case series.
\end{abstract}

ABBREVIATIONS: PPS = parapharyngeal space; $\mathrm{VM}=$ venous malformation

V

enous malformations (VMs) are typically considered unencapsulated, circumscribed, or trans-spatial lesions comprising dysplastic serpentine sinusoids that may contain phleboliths. Although "cavernous hemangioma" is a colloquial term that remains in use, it has been increasingly recognized that many such lesions are actually low-flow VMs as opposed to hemangiomas, with the latter being a true neoplasm. ${ }^{1-4}$ In 1982, Mulliken and Glowacki ${ }^{5}$ proposed a biologic classification scheme that categorized vascular anomalies on the basis of the rate of cell turnover, histology, natural history, and examination findings. The current International Society for the Study of Vascular Anomalies classification system is grounded in this sentinel work, which groups vascular anomalies into 2 categories: tumors and malformations. ${ }^{4}$ The most common vascular tumor is infantile hemangioma, while VM is the most common vascular malformation.

Parapharyngeal space (PPS) masses are uncommon, composing only $0.5 \%$ of all head and neck tumors. ${ }^{6}$ Of these, VMs represent $<1 \%$ of all PPS masses. ${ }^{7}$ Salivary gland tumors, most com-

Received June 22, 2018; accepted after revision September 4

From the Departments of Radiology (C.M.T., G.P.F., J.M.H.) and Laboratory Medicine and Pathology (T.K.L.), Mayo Clinic, Phoenix, Arizona; Department of Radiology (C.P.W.), Mayo Clinic, Rochester, Minnesota; and Department of Radiology (S.M.W.), Mayo Clinic, Jacksonville, Florida.

Paper previously presented at: Annual Meeting of the American Society of Head and Neck Radiology, September 16-20, 2017; Las Vegas, Nevada.

Please address correspondence to Joseph M. Hoxworth, MD, Mayo Clinic, Department of Radiology, 5777 E Mayo Blvd, Phoenix, AZ 85054; e-mail: hoxworth.joseph@mayo.edu

Indicates article with supplemental on-line table

http://dx.doi.org/10.3174/ajnr.A5859 monly pleomorphic adenomas, account for $40 \%-50 \%$ of all PPS tumors, arising either primarily from minor salivary rests or secondarily encroaching on the PPS from the deep parotid lobe. ${ }^{7-9}$

Both VM and pleomorphic adenoma may appear as a wellcircumscribed, mildly lobulated enhancing mass that is isodense to muscle on CT and markedly T2 hyperintense on MR imaging. ${ }^{1,3,10,11}$ As a result, distinguishing these 2 entities when they occur in the PPS can be challenging, and this distinction is clinically important because management for salivary gland tumor and VM may differ. To date, very few case reports have published the imaging features of patients with primary PPS VMs, which have been frequently described as "hemangiomas," reflecting the controversial ongoing use of older nomenclature. ${ }^{12-16}$ The primary aim of this study was to review the imaging appearance of PPS VMs via a retrospective case series and to seek specific imaging features that may allow differentiation from benign salivary gland tumors such as pleomorphic adenoma.

\section{Case Series}

This retrospective study was approved by the institutional review board at the Mayo Clinic with a waiver of informed consent. The pathology data base was electronically queried from 2000 to 2017 using a keyword search. Patients with pathologically confirmed PPS VMs were identified, and those with pretreatment CT and/or MR imaging were included. Demographic and clinical data were obtained from the electronic medical record. The imaging appearance of these lesions, including CT density, MR imaging signal characteristics, enhancement pattern, the presence or absence of calcification, the relationship to adjacent structures, size, and 
stability (On-line Table), was characterized through a detailed review by a board-certified neuroradiologist.

Six patients met the inclusion criteria, 5 women and 1 man (34-76 years of age; mean, 59 years). All lesions were identified incidentally on imaging studies obtained for an unrelated clinical problem, which included headache, tongue numbness (contralateral to the side of the VM), multiple sclerosis, cervical spondylosis, and staging work-up for sinonasal carcinoma. Following initial detection, all patients were evaluated by a head and neck surgeon, and none of the masses were palpable externally. Typically following a bloody acellular aspirate, diagnosis was established with CTguided core biopsy in 4 patients and with surgical resection in 2 patients. Three of the lesions were diagnosed as PPS VMs at the time of tissue sampling, while the remaining 3 were initially characterized as cavernous hemangiomas but later confirmed to be VMs at the time of study inclusion.

All VMs were located in the prestyloid PPS. ${ }^{17,18}$ Four were right-sided, 2 were left-sided, and only 2 contacted the deep lobe of the parotid gland. Maximum dimensions ranged from 1.3 to
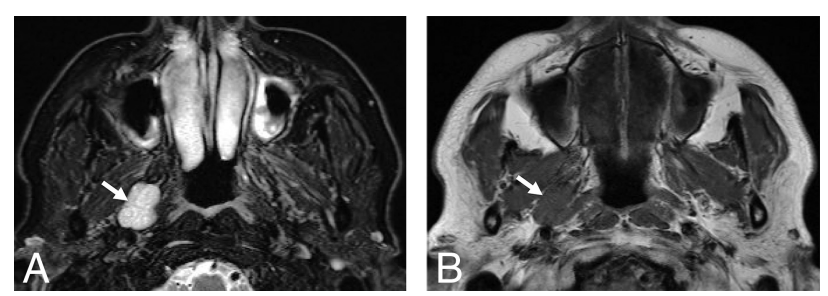

FIG 1. Typical MR imaging signal characteristics of a VM (white arrow) in the right PPS of a 56-year-old woman. A, Axial fat-suppressed T2weighted MR imaging depicts a well-circumscribed lobulated markedly hyperintense PPS mass. $B$, Axial TT-weighted MR imaging shows the mass as isointense to skeletal muscle.
$2.2 \mathrm{~cm}$, while volume (ROI Volume tool, OsiriX Imaging Software; Version 9.0, http://www.osirix-viewer.com) ranged from 0.8 to $5.5 \mathrm{~cm}^{3}$ (mean, $2.3 \pm 1.7 \mathrm{~cm}^{3}$ ).

All MR imaging scans were of good technical quality with no need for repeat imaging. On MR imaging, all VMs were welldefined and, relative to skeletal muscle, appeared markedly hyperintense on T2WI and isointense-to-minimally hyperintense on precontrast T1WI (Fig 1). Postgadolinium T1WI was available for review in all 6 patients and revealed highly variable enhancement patterns (Fig 2). Heterogeneously diffuse enhancement and stippled enhancement were each seen in $2 \mathrm{VMs}$, while single lesions demonstrated homogeneous diffuse enhancement and focal central enhancement, respectively. Four of 6 VMs demonstrated a qualitatively greater volume of lesion enhancement on the more delayed of the 2 consecutive postgadolinium sequences (Fig $2 F$ ). All postgadolinium T1WI used fat suppression, with the axial plane obtained first and immediately followed by the coronal acquisition.

On noncontrast CT, all of the PPS VMs were isodense to skeletal muscle and none contained phleboliths or other calcifications. Only 1 patient had postcontrast CT images that demonstrated enhancement of the central portion of the lesion (Fig 2D).

Sonography, available for review in 2 patients, demonstrated well-defined masses that were minimally hyperechoic compared with the pterygoid muscles (Fig 3). Identifiable vessels within the masses exhibited venous waveforms. Intraoral sonography, which was pursued in both patients to evaluate candidacy for transoral resection, allowed better proximity to the PPS to improve image quality.

Most patients had no follow-up imaging in our institution after biopsy or surgical resection. In 1 patient, the VM was stable at 8 months following biopsy. In a second patient, the lesion was $60 \%$ smaller by volume 5 years following core biopsy.

All MR imaging and CT studies were initially interpreted by a
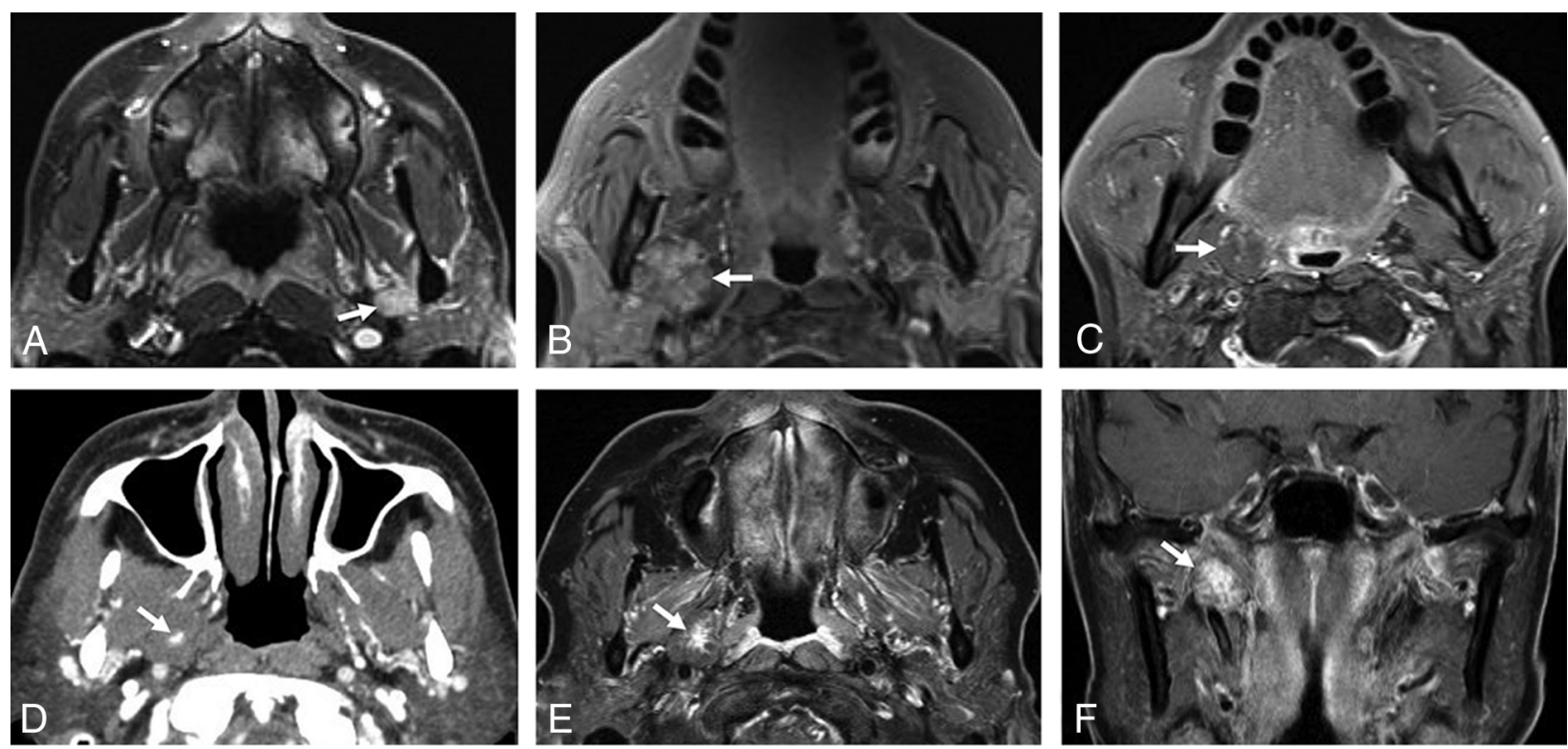

FIG 2. Variable enhancement patterns of PPS VMs (white arrows). A, Axial T1-weighted fat-suppressed postcontrast MR imaging in a 34-year-old man demonstrates diffuse homogeneous enhancement. B. Axial T1-weighted fat-suppressed postcontrast MR imaging from a 66-year-old woman illustrates a diffuse heterogeneous enhancement pattern. C, Axial T1-weighted fat-suppressed postcontrast MR imaging from a 61-yearold woman depicts stippled enhancement. Axial contrast-enhanced CT (D), axial T1-weighted fat-suppressed postcontrast MR imaging (E), and coronal T1-weighted fat-suppressed postcontrast MR imaging $(F)$ from a 56 -year-old woman. The axial CT and MR imaging demonstrate focal central enhancement, while the coronal image, which was acquired after additional time had elapsed following the intravenous contrast infusion, illustrates progressively more diffuse contrast enhancement. 

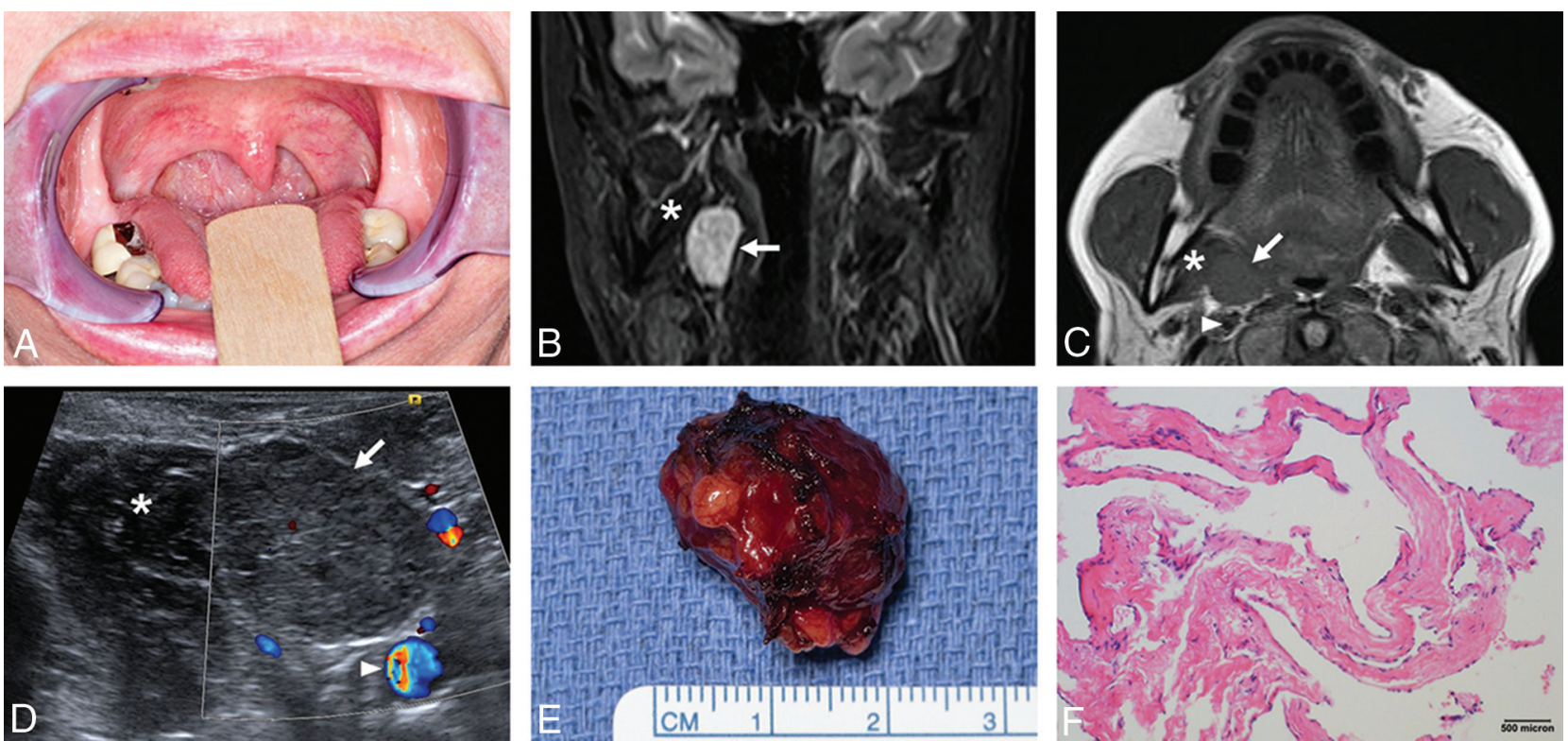

FIG 3. Clinicopathologic correlation for a right PPS VM in a 61-year-old woman. A, Intraoral photograph demonstrates subtle right pharyngeal fullness with mild leftward deviation of the uvula. $B$, Coronal fat-suppressed T2-weighted MR imaging demonstrates a homogeneously hyperintense right PPS mass. C, Axial T1-weighted MR imaging depicts a round, well-circumscribed mass that is minimally hyperintense relative to skeletal muscle with effacement of the right parapharyngeal fat. $D$, Intraoral sonography illustrates the close relationship to the medial pterygoid muscle and the internal carotid artery. The VM is slightly hyperechoic compared with skeletal muscle. E, Gross pathologic specimen demonstrates the lobulated shape of this VM, correlating with the sonographic findings. F, Hematoxylin-eosin-stained photomicrograph illustrates nonanastomosing dilated endothelial-lined spaces, and the endothelial cells lack atypia. These findings are consistent with VM. VM (arrow), medial pterygoid muscle (asterisk), internal carotid artery (arrowhead).

board-certified neuroradiologist. On the basis of review of the radiology reports, salivary gland tumor or, more specifically, pleomorphic adenoma was the most commonly suggested diagnosis before tissue sampling in 5 of 6 patients. One lesion was thought to represent a metastatic lymph node in an aggressive sinonasal carcinoma. The possibility of a VM was not suggested in the radiology report differential diagnosis before tissue diagnosis in any of our patients.

\section{DISCUSSION}

Evaluation of head and neck vascular anomalies is heavily dependent on MR imaging, which has excellent spatial resolution and soft-tissue contrast, allowing both lesion characterization and assessment of extent for pretreatment planning. ${ }^{1-3,19,20}$ This dependence on MR Imaging is particularly true for PPS VMs, which may not be detectable by palpation or skin discoloration. Because of the rich slow-flowing venous blood supply, VMs are T2 hyperintense and $\mathrm{T} 1$ intermediate on MR imaging, and signal voids may be present in the case of phleboliths. VM enhancement is often patchy and delayed, demonstrating sequential filling of the lesion with slow washout. At our institution, postgadolinium T1WI sequences are first obtained in the axial plane approximately 90 seconds postinjection and take approximately 5 minutes to acquire. The subsequent coronal postgadolinium T1WI acquisition begins approximately $6-7$ minutes postinjection. In 4 of 6 patients, the PPS VM demonstrated increased enhancement on the delayed coronal postgadolinium images, best characterized as contrast filling-in the mass to a greater degree.

Unenhanced CT may be used as an adjunctive tool to assess phleboliths in VM. In our series, none of the VMs contained phle- boliths, but they have indeed been reported in PPS VMs. ${ }^{12}$ As a result, there is a high likelihood that the absence of phleboliths in the current series represents a sampling bias, given the small size of our cohort. While phleboliths are considered pathognomonic for VMs, 1 study of head and neck VMs reported phleboliths in only $28.6 \%$, though a rigorous, uniform imaging approach was not used for phlebolith identification. ${ }^{21}$

Although sonography is useful for the assessment of soft-tissue vascular anomalies, ${ }^{22}$ lesions deep in the PPS may be difficult to adequately visualize. Intraoral endosonography (Fig $3 D$ ) may be performed using an endocavitary probe if the lesion is located medially in the PPS. This can be a useful adjunct for planning transoral surgery, which is an increasingly viable approach for PPS lesions. ${ }^{23}$ At sonography, VMs appear as lobulated hypoechoic masses with small internal venous channels. ${ }^{3}$ On spectral Doppler imaging, waveforms are venous, and a curvilinear hyperechoic focus with posterior shadowing may be identified if phleboliths are present.

Although vascular malformations are more likely to be transspatial and less well-defined than hemangiomas, ${ }^{22}$ all of the PPS VMs in our series appeared as lobulated, well-circumscribed soft-tissue masses, which is concordant with other reports. ${ }^{12-16}$ This imaging appearance can lead to diagnostic uncertainty, with PPS VMs being mistaken for the much more common pleomorphic adenoma because both can occur with or without a connection to the deep lobe of the parotid gland. Several imaging features may assist in differentiating PPS VM from pleomorphic adenoma. First, although PPS pleomorphic adenomas may calcify with greater frequency than those within the parotid gland (50\% versus $15 \%$ ), the calcification is more likely to be coarse or punctate, ${ }^{11}$ which differs from the typical laminated appearance of a phlebolith. ${ }^{21}$ Second, PPS VMs are more 
commonly homogeneously $\mathrm{T} 2$ hyperintense compared with muscle, while pleomorphic adenomas in the PPS may exhibit T2 isointensity or hypointensity within their solid components secondary to hypercellularity with less myxoid stroma. ${ }^{11,24}$ Last, two-thirds of PPS VMs in our series demonstrated progressive contrast pooling on routine delayed postcontrast MR imaging (ie, without performing dedicated dynamic contrast-enhanced imaging). Although pleomorphic adenomas can slowly accumulate and retain intravenous contrast, ${ }^{24,25}$ the pattern of initial central or stippled enhancement with delayed filling-in seen with some VMs is less characteristic of pleomorphic adenomas.

In a systematic review of 1293 cases of PPS masses by Kuet et $\mathrm{al},{ }^{7}$ the most common clinical presentations were cervical mass and intraoral swelling. In contrast to our series, none of the published reports that they reviewed were based on incidental findings from imaging. Patients are more likely to present with a detectable PPS mass when the lesion measures $>2.5-3.0 \mathrm{~cm},{ }^{26,27}$ so the small size of the VMs in our series is concordant with incidental detection. Certainly, large PPS VMs can become palpable and symptomatic. ${ }^{12}$ Symptoms that should raise concern for malignancy include referred otalgia, facial pain, trismus, and cranial nerve involvement. ${ }^{7,27}$ None of the patients in our series demonstrated any of these worrisome symptoms.

The primary limitations of the current case series are its small size and retrospective methodology, though the imaging features of these uncommon PPS VMs were relatively consistent throughout the cohort. Comparison of the current results with the few previously published reports of PPS VM imaging features is also limited because we must presume that previous reports describing PPS "hemangiomas" in adult patients were indeed referring to VMs.

\section{CONCLUSIONS}

Because of their rarity, PPS VMs are difficult to diagnose prospectively on MR imaging and CT and, when small, may be encountered incidentally on imaging studies obtained for other reasons. This lesion can present a diagnostic dilemma related to overlapping location and imaging characteristics of the much more common PPS pleomorphic adenoma. With heightened awareness of VMs occurring in the PPS and their typical imaging features, the radiologist may appropriately include VM in the differential diagnosis of a PPS mass.

\section{REFERENCES}

1. Baker LL, Dillon WP, Hieshima GB, et al. Hemangiomas and vascular malformations of the head and neck: MR characterization. AJNR Am J Neuroradiol 1993;14:307-14 Medline

2. Lowe LH, Marchant TC, Rivard DC, et al. Vascular malformations: classification and terminology the radiologist needs to know. Semin Roentgenol 2012;47:106-17 CrossRef Medline

3. Steinklein JM, Shatzkes DR. Imaging of vascular lesions of the head and neck. Otolaryngol Clin North Am 2018;51:55-76 CrossRef Medline

4. Wassef M, Blei F, Adams D, et al; ISSVA Board and Scientific Committee. Vascular anomalies classification: recommendations from the International Society for the Study of Vascular Anomalies. $\mathrm{Pe}$ diatrics 2015;136:e203-14 CrossRef Medline

5. Mulliken JB, Glowacki J. Hemangiomas and vascular malformations in infants and children: a classification based on endothelial characteristics. Plast Reconstr Surg 1982;69:412-22 CrossRef Medline
6. Batsakis JG, Sneige N. Parapharyngeal and retropharyngeal space diseases. Annals of Otology, Rhinology \& Laryngology 1989;98:320-21 CrossRef Medline

7. Kuet ML, Kasbekar AV, Masterson L, et al. Management of tumors arising from the parapharyngeal space: a systematic review of 1,293 cases reported over 25 years. Laryngoscope 2015;125: 1372-81 CrossRef Medline

8. Khafif A, Segev Y, Kaplan DM, et al. Surgical management of parapharyngeal space tumors: a 10-year review. Otolaryngol Head Neck Surg 2005;132:401-06 CrossRef Medline

9. Hughes KV 3rd, Olsen KD, McCaffrey TV. Parapharyngeal space neoplasms. Head Neck 1995;17:124-30 CrossRef Medline

10. Ikeda K, Katoh T, Ha-Kawa SK, et al. The usefulness of MR in establishing the diagnosis of parotid pleomorphic adenoma. AJNR Am J Neuroradiol 1996;17:555-59 Medline

11. Kato H, Kanematsu M, Mizuta K, et al. Imaging findings of parapharyngeal space pleomorphic adenoma in comparison with parotid gland pleomorphic adenoma. Jpn J Radiol 2013;31:724-30 CrossRef Medline

12. Cho JH, Joo YH, Kim MS, et al. Venous hemangioma of parapharyngeal space with calcification. Clin Exp Otorhinolaryngol 2011;4: 207-09 CrossRef Medline

13. Gennaro P, Chisci G, Gabriele G, et al. Management of a bulky capillary hemangioma in the parapharyngeal space with minimally invasive surgery. J Craniofac Surg 2014;25:e161-63 CrossRef Medline

14. Granell J, Alonso A, Garrido L, et al. Transoral fully robotic dissection of a parapharyngeal hemangioma. J Craniofac Surg 2016;27: 1806-07 CrossRef Medline

15. Kale US, Ruckley RW, Edge CJ. Cavernous haemangioma of the parapharyngeal space. Indian J Otolaryngol Head Neck Surg 2006;58: 77-80 Medline

16. Surasi DS, Meibom S, Grillone G, et al. F-18 FDG PET/CT imaging of a parapharyngeal hemangioma. Clin Nucl Med 2010;35:612-13 CrossRef Medline

17. Curtin HD. Separation of the masticator space from the parapharyngeal space. Radiology 1987;163:195-204 CrossRef Medline

18. Gupta A, Chazen JL, Phillips CD. Imaging evaluation of the parapharyngeal space. Otolaryngol Clin North Am 2012;45:1223-32 CrossRef Medline

19. Baer AH, Parmar HA, DiPietro MA, et al. Hemangiomas and vascular malformations of the head and neck: a simplified approach. Neuroimaging Clin N Am 2011;21:641-58, viii CrossRef Medline

20. Donnelly LF, Adams DM, Bisset GS 3rd. Vascular malformations and hemangiomas: a practical approach in a multidisciplinary clinic. AJR Am J Roentgenol 2000;174:597-608 CrossRef Medline

21. Eivazi B, Fasunla AJ, Guldner C, et al. Phleboliths from venous malformations of the head and neck. Phlebology 2013;28:86-92 CrossRef Medline

22. Paltiel HJ, Burrows PE, Kozakewich HP, et al. Soft-tissue vascular anomalies: utility of US for diagnosis. Radiology 2000;214:747-54 CrossRef Medline

23. Duek I, Sviri GE, Billan S, et al. Minimally invasive surgery for resection of parapharyngeal space tumors. J Neurol Surg B Skull Base 2018;79:250-56 CrossRef Medline

24. Motoori K, Yamamoto S, Ueda T, et al. Inter- and intratumoral variability in magnetic resonance imaging of pleomorphic adenoma: an attempt to interpret the variable magnetic resonance findings. $J \mathrm{Com}$ put Assist Tomogr 2004;28:233-46 CrossRef Medline

25. Lev MH, Khanduja K, Morris PP, et al. Parotid pleomorphic adenomas: delayed CT enhancement. AJNR Am J Neuroradiol 1998; 19:1835-39 Medline

26. Som PM, Biller HF, Lawson W, et al. Parapharyngeal space masses: an updated protocol based upon 104 cases. Radiology 1984;153: 149-56 CrossRef Medline

27. Carrau RL, Myers EN, Johnson JT. Management of tumors arising in the parapharyngeal space. Laryngoscope 1990;100:583-89 CrossRef Medline 